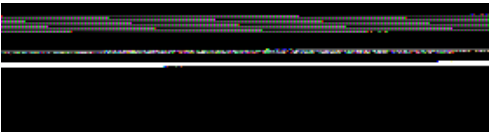

This information is current as of April 25, 2023.
Asymptomatic Interhypothalamic Adhesions in Children

F.N. Ahmed, N.V. Stence and D.M. Mirsky

AJNR Am J Neuroradiol 2016, 37 (4) 726-729

doi: https://doi.org/10.3174/ajnr.A4602

http://www.ajnr.org/content/37/4/726 


\title{
Asymptomatic Interhypothalamic Adhesions in Children
}

(D)F.N. Ahmed, (DN.V. Stence, and (DD.M. Mirsky

\begin{abstract}
SUMMARY: With the use of high-resolution MR imaging techniques, we have increasingly observed anomalies of the hypothalamus characterized by a band of tissue spanning the third ventricle between the hypothalami, often without associated clinical sequelae. Historically, hypothalamic anomalies are highly associated with symptoms referable to a hypothalamic hamartoma, midline congenital disorder, hypothalamic-pituitary dysfunction, or seizures, with very few asymptomatic patients reported. The interhypothalamic tissue described in our cohort was observed incidentally through the routine acquisition of high-resolution TIWI. No referable symptoms were identified in most of the study group. In the appropriate patient population in which associated symptoms are absent, the described hypothalamic anomalies may be incidental and should not be misdiagnosed as hypothalamic hamartomas.
\end{abstract}

ABBREVIATIONS: GMH = gray matter heterotopia; IHA = interhypothalamic adhesion

A nomalies of the hypothalamus have generally been thought to come in 2 forms, hypothalamic hamartoma or hypothalamic dysgenesis associated with midline congenital disorders such as holoprosencephaly spectrum or septo-optic dysplasia. ${ }^{1-3}$ Classically, hypothalamic abnormalities are associated with symptoms of central endocrinologic dysfunction and/or seizures. Few asymptomatic patients have been reported. ${ }^{4-8}$ Most of these cases were associated with other disorders, such as neurofibromatosis type $1 .{ }^{9}$

With the routine use of high-resolution, isotropic T1 imaging, we have observed a thin band of tissue connecting the medial hypothalamic regions, spanning the anterior recess of the third ventricle, in a group of patients lacking symptoms of diencephalic dysfunction. This finding was recently described in 2 separate case series as an interhypothalamic adhesion (IHA). ${ }^{4,5}$ In these articles, however, IHAs were commonly associated with multiple congenital anomalies. Our objective was to analyze the MRI of our patient cohort with IHA and correlate these findings with

Received August 7, 2015; accepted after revision September 20.

From the Department of Radiology (F.N.A.), University of Colorado Anschutz Medical Campus, Aurora, Colorado; and Department of Radiology (N.V.S., D.M.M.), Children's Hospital Colorado, Aurora, Colorado.

Paper previously presented as a poster ("Interhypothalamic Adhesion in Asymptomatic Children") at: American Society of Neuroradiology Annual Meeting and the Symposium of the ASNR Foundation, April 25-30, 2015; Chicago, Illinois.

Please address correspondence to David M. Mirsky, MD, Department of Radiology, Children's Hospital Colorado, 13123 East 16th Ave, Box B125, Aurora, CO 80045;

e-mail: David.Mirsky@childrenscolorado.org

http://dx.doi.org/10.3174/ajnr.A4602 other brain anomalies and clinical presentations to determine the significance, if any, of this finding.

\section{MATERIALS AND METHODS}

After institutional review board approval, the case file data base of Children's Hospital Colorado was searched for patients identified with hypothalamic anomalies on MR imaging between 2009 and 2014. All imaging was performed at Children's Hospital Colorado on a variety of MR imaging systems, including Avanto 1.5T (Siemens, Erlangen, Germany), Achieva 1.5T (Philips Healthcare, Best, the Netherlands), and Ingenia 1.5T or 3T (Philips Healthcare). Images were reviewed by 2 pediatric neuroradiologists (D.M.M. and N.V.S.) for a band of tissue spanning the third ventricle connecting the medial portions of the hypothalamus. Other structural abnormalities were also recorded, including lack of midline cleavage, pituitary anomalies, and cortical malformations. The band of tissue was measured on MR imaging and, as performed in a previously published smaller case series, the possible nuclei involved in the hypothalamic connection were inferred from the segmentation scheme devised by Lemaire et $\mathrm{al}^{10}$ on the basis of anatomic landmarks. ${ }^{5}$

Hypothalamic dysfunction was surmised from history and clinical symptoms. The patients' charts were reviewed by using the Epic electronic medical record system (Epic Systems, Madison, Wisconsin) at Children's Hospital Colorado for their medical history and symptomology. Patients were then characterized into 3 groups: 1) no symptoms referable to the hypothalamus, 2) symptoms that could be associated with the hypothalamus, and 3) symptoms of indeterminate relevance to the hypothalamus. 
Both symptomatic groups (those with symptoms possibly attributable to the hypothalamus and symptoms of uncertain relationship to the hypothalamus) were then treated as 1 cohort.

\section{RESULTS}

The inclusion criteria from the case file data base resulted in 60 patients. Three were excluded because they had a diagnosis of

Table 1: IHA demographics and imaging indications of the cohort

\begin{tabular}{lccc}
\hline & $\begin{array}{c}\text { No Referable } \\
\text { Symptoms }\end{array}$ & Symptomatic $\boldsymbol{P}$ Value \\
\hline Total & 40 & 17 & \\
Demographics & & & \\
$\quad$ Male & 20 & 7 & .54 \\
$\quad$ Female & 20 & 10 & .54 \\
Average age (yr) & 6.1 & 10.2 & .30 \\
Age range & 8 Days to & 11 Months to & \\
& 20 years & 17 years & \\
Imaging indication & & & \\
$\quad$ Seizures & 9 & 5 & .58 \\
Developmental delays & 8 & 3 & .84 \\
Headaches/migraines & 4 & 0 & .18 \\
Vision problems & 4 & 1 & .62 \\
Hearing problems & 2 & 0 & .35 \\
Trauma & 2 & 0 & .35 \\
Chiari diagnosed in utero & 2 & 0 & .35 \\
Short stature & 1 & 2 & .15 \\
Fetal alcohol syndrome & 1 & 1 & .53 \\
$\quad$ Other & $8^{\mathrm{a}}$ & $5^{\mathrm{b}}$ & \\
\hline
\end{tabular}

a Tongue hemihypertrophy, myelomeningocele, scalp mass, Horner syndrome, multiple sclerosis, lower extremity pain, and spasms.

${ }^{b}$ Craniosynostosis, hydrocephalus on fetal ultrasound, panhypopituitarism, and hypothyroidism.
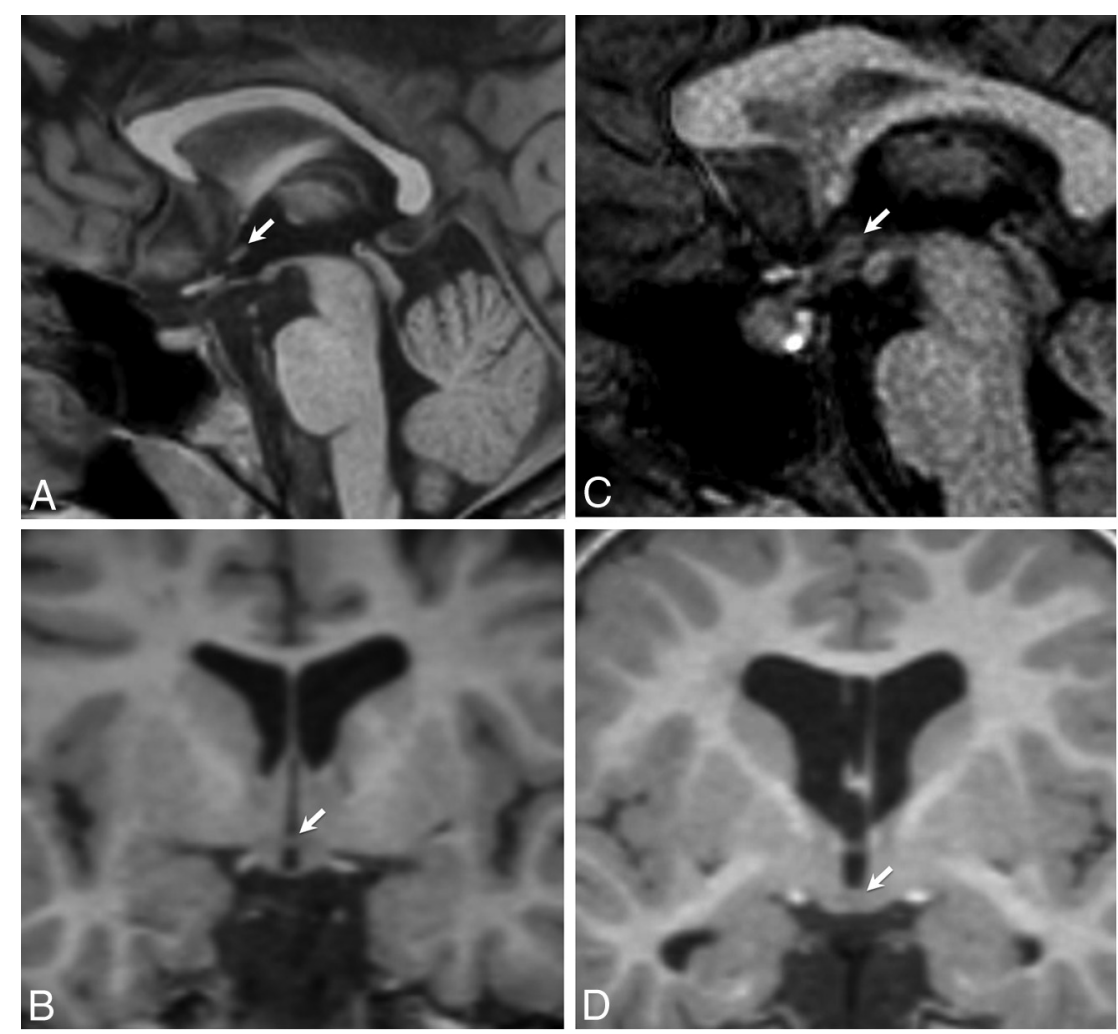

neurofibromatosis, which has been reported in association with hypothalamic hamartomas. ${ }^{9}$ This exclusion resulted in a study cohort of 57 patients of equal sex distribution, ranging in age from 5 days to 20 years (mean age, 7.3 years). MR imaging indications for the group included vertigo, concussion, trauma, tongue hypertrophy, seizures, developmental delays, visual problems, and premature birth. See Table 1 for complete demographic details and indications.

In all cases, the hypothalamic anomaly consisted of a band of tissue spanning the anterior recess of the third ventricle, which appeared linear in the axial and coronal planes and nodular in the sagittal plane (Fig 1). In all patients, the band of tissue was T2 isointense to gray matter and did not contact the mammillary bodies or extend below the tuber cinereum.

The average volume of the hypothalamic connection was 59.2 $\mathrm{mm}^{3}$, with asymptomatic patients having an average volume of $48.8 \mathrm{~mm}^{3}$, and symptomatic ones having an average volume of $78.0 \mathrm{~mm}^{3}(P=.035)$. In most cases, the band of tissue closely approximated the dorsomedial hypothalamic nuclei, followed by the ventromedial hypothalamic nuclei (Fig 2).

Of the 57 patients with IHAs, 18 had otherwise normal MR imaging examinations. Twenty-three had gray matter heterotopia (GMH). Four had findings consistent with septo-optic dysplasia. Chiari malformations were present in 3 patients, 2 with Chiari I and 1 with Chiari II. Abnormalities of the septum pellucidum were present in 7 individuals. Complete imaging findings are described in Table 2.

Forty of the 57 patients had no clinical symptoms referable to their IHA. The IHA was considered an incidental finding in these cases and documented as such in their medical charts. Of these, 18

FIG 1. A band of tissue spanning the anterior recess of the third ventricle that appeared linear in the axial and coronal planes and nodular in the sagittal plane as seen on 3T TIWI. A and B, A flat band of tissue behind the lamina terminalis. C and D, A flat band of tissue above the tuber cinereum. $E$ and $F, A$ nodular band of tissue contacting both lamina terminalis and tuber cinereum. 

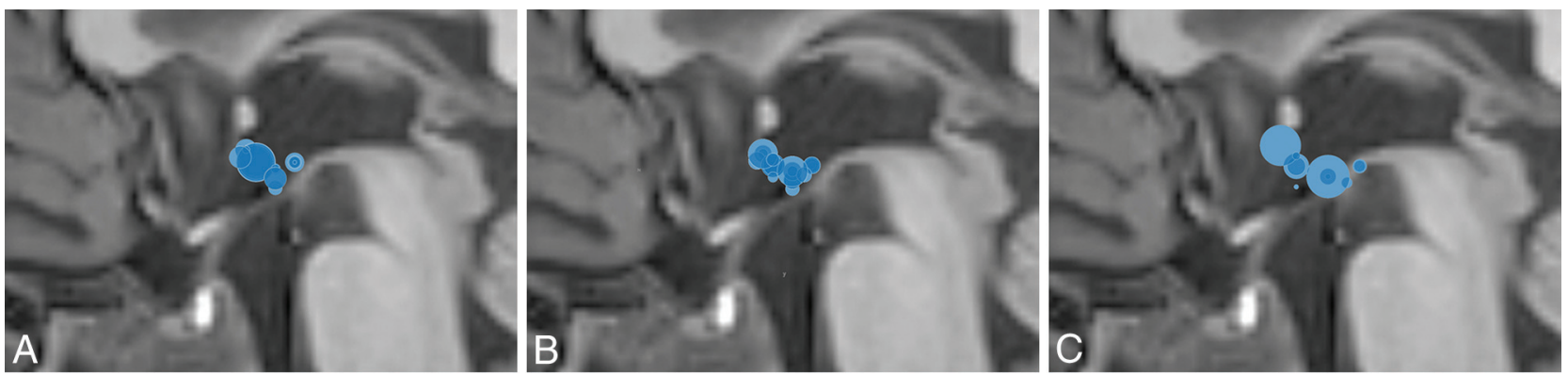

FIG 2. Position maps of the interhypothalamic adhesions. A, All IHAs in our study. B, Asymptomatic IHAs. C, Symptomatic IHAs.

Table 2: Imaging characteristics of the cohort: structural features by imaging

\begin{tabular}{lccc}
\hline & $\begin{array}{c}\text { No Referable } \\
\text { Symptoms }\end{array}$ & Symptomatic & $\boldsymbol{P}$ Value \\
\hline IHA volume $\left(\mathrm{mm}^{3}\right)$ & 48.8 & 78 & .04 \\
Otherwise normal & 14 & 4 & .39 \\
Gray matter & 17 & 6 & .61 \\
$\quad$ heterotopias & & & \\
Septo-optic dysplasia & 0 & 4 & .001 \\
$\quad$ Chiari malformation & 3 & 0 & .25 \\
Periventricular & 2 & 1 & .89 \\
$\quad$ leukomalacia & & & \\
Neoplasm & 2 & 0 & .35 \\
Polymicrogyria & 0 & 1 & .12 \\
Other & $8^{\text {a }}$ & $6^{\text {b }}$ & \\
\hline
\end{tabular}

${ }^{\text {a }}$ Dilated perivascular spaces, multiple sclerosis with a velum interpositum, right cochlear nerve hypoplasia, right cerebral closed lip schizencephaly, vermian hypoplasia, sinus pericranii, and 2 isolated cases of cavum septum pellucidum.

${ }^{b}$ Abnormal sulcation, transmantle cortical dysplasia, frontonasal dysplasia, inferior vermian hypoplasia with absent septum pellucidum, cavum septum pellucidum (with septo-optic dysplasia), and velum interpositum.

Table 3: Clinical symptoms of the cohort

\begin{tabular}{lccc}
\hline & $\begin{array}{c}\text { No Referable } \\
\text { Symptoms }\end{array}$ & Symptomatic & $\boldsymbol{P}$ Value \\
\hline Healthy & $18^{\mathrm{a}}$ & 0 & $<.01$ \\
Seizures & $9^{\mathrm{b}}$ & 5 & .58 \\
$\begin{array}{l}\text { Endocrine problems } \\
\text { Mild developmental }\end{array}$ & 0 & 3 & $<.01$ \\
$\quad 8$ & 6 & .22 \\
$\quad \begin{array}{l}\text { delays } \\
\quad \text { devere developmental }\end{array}$ & 0 & 8 & $<.01$ \\
$\quad \begin{array}{l}\text { Heart anomalies } \\
\text { Sensory hearing loss }\end{array}$ & 3 & 0 & .25 \\
Premature birth & 2 & 0 & .35 \\
\hline
\end{tabular}

${ }^{a}$ Four of these individuals had initially presented with headaches, and 1, with vertigo, all considered to be isolated issues without ongoing symptoms at the time of this review. All 3 individuals with Chiari malformations were included in the group lacking referable symptoms. Two additional patients had presented with trauma and were healthy after their other musculoskeletal injuries healed. Two more of these patients were evaluated for unilateral sensory hearing loss but were considered clinically healthy otherwise. An individual with a low-grade glial neoplasm had originally presented with a seizure but had no other symptoms after resection. One individual with multiple sclerosis had 2 episodes of lower extremity weakness and tingling that had resolved. The remaining patients lacking symptoms referable to the IHA had presenting symptoms that resolved with treatment or conservative measures (tongue hemihypertrophy with an arteriovascular malformation, scalp mass [sinus pericranii], Horner syndrome, lower extremity pain, and spasms).

${ }^{\mathrm{b}}$ Born at 26-34 weeks' gestation.

patients were completely asymptomatic at last follow-up and were considered healthy. Of the 17 symptomatic patients, 8 individuals had symptoms that could be attributable to an IHA while 9 had nonlocalizable symptoms. Complete clinical findings are described in Table 3 .
Fourteen patients of the entire cohort of 57 had persistent seizures. Nine of these patients were thought to lack symptoms referable to the IHA; 8 had an epileptic focus identified on electroencephalography outside the hypothalamus, and the ninth had seizures thought to be related to a pineoblastoma. The remaining 5 patients with seizures had no identifiable focus ( 3 individuals) or other global deficits ( 2 individuals) and were included in the symptomatic group. No patient had gelastic seizures.

Three patients with endocrine dysfunction were placed in the symptomatic category because causation could not be decided with certainty. One of these patients had delayed puberty and short stature; another presented with dwarfism, growth hormone deficiency, and Duchenne muscular dystrophy variant; and the third presented with central hypothyroidism.

Mild developmental delays (as determined by chart review when growth and verbal and/or reading milestones were not met) were present in 14 individuals. Eight of these patients were thought to lack symptoms definitely referable to the IHA, while the others had indeterminate symptoms, endocrine problems, or nonlocalizable seizures.

Eight patients had severe developmental delays documented in the medical record and were all categorized into the symptomatic group. Findings of 4 of these individuals were on the septo-optic dysplasia spectrum, which has been previously correlated with IHAs. $^{11}$

\section{DISCUSSION}

Interhypothalamic adhesion has been defined as a linear band of tissue spanning the medial hypothalamic walls, similar in appearance to the normal interthalamic adhesion. Only 2 reports in the literature describe this entity. ${ }^{4,5}$ The first report in 2013 characterized a single patient presenting with IHA in association with a cleft palate deformity. ${ }^{4}$ The second report in 2014 was a case series of 13 patients in which most IHAs were thought to be associated with other midline structural abnormalities. In our cohort of 57 patients, 40 (70\%) lacked clinical symptoms referable to the hypothalamus. Furthermore, after careful scrutiny, 14 of those 40 individuals had otherwise normal brains. None had midline developmental defects including but not limited to hippocampal dysgenesis or under-rotation, hypoplastic falx, olfactory hypoplasia, and optic pathway hypoplasia. In most of our patients, IHA represented an isolated finding that was thought to be of no clinical significance.

Most IHAs in our cohort closely approximated the dorsomedial and ventromedial nuclei of the hypothalamus, similar to the 
2014 report $^{4}$; however, we have no pathologic evidence of true involvement of these nuclei. It is possible that this tissue merely bridges the medial surfaces of the hypothalamus. In the literature, human hypothalamic development is not well-understood, and information about it relies heavily on animal studies. ${ }^{12-14} \mathrm{~A}$ pathologic observational study done by Koutcherov et $\mathrm{al}^{14}$ described a transient midline hypothalamic structure observed during fetal development. No other midline hypothalamic structure has been described. IHAs may represent a focus of failed apoptosis versus migration or accessory hypothalamic tissue. The lack of evidence of hypothalamic-pituitary axis dysfunction or seizures in most patients, in and of itself in our cohort, suggests that the band of tissue is often not of clinical or pathologic significance.

Gray matter heterotopia was discovered in 23 of 57 patients $(40 \%)$ in our IHA cohort. Of these patients, 17 had subependymal heterotopia, 3 had focal subcortical heterotopia, and 3 had band heterotopia. The coexistence of IHA and GMH in our population suggests that the combination may be part of an, as of yet, undescribed genetic disorder. This also raises the possibility that an IHA may be a rest of neuronal tissue from failed migration. The clinical relevance of both findings remains uncertain, particularly because 6 of our patients with both IHA and GMH were completely asymptomatic and midline anomalies were absent in most patients.

Distinguishing IHA from other hypothalamic pathology, such as hamartoma or glioma, requires high-resolution imaging in all 3 planes. In the sagittal plane, both IHA and hamartomas can appear nodular or masslike. IHAs, however, span the hypothalamic medial regions as a linear band of tissue in the axial and coronal planes, while a hamartoma is typically nodular in all 3 planes. Furthermore, a hamartoma often involves one of the hypothalamic surfaces asymmetrically more than the other and often contacts or invades the mammillary bodies. IHAs symmetrically involve the hypothalamic walls and do not contact the mammillary bodies. Hypothalamic gliomas are easier to distinguish because they are typically not isointense to gray matter and often enhance following contrast administration. One potential pitfall that could lead to misdiagnosis of IHA is a diminutive third ventricle, where the opposed medial surfaces of the hypothalamus can mimic a hypothalamic anomaly in the sagittal plane. In our experience, this occurs most frequently in patients with a ventriculoperitoneal shunt and decompressed ventricles. High-resolution imaging in all 3 planes avoids this confusion because the pseudolesion will not be verified in the axial and coronal planes.

Our study is limited by its retrospective bias. The available medical records limit assessment of clinical symptoms because no direct evaluation of subjects could be performed. Because an IHA is a subtle finding, it could have been easily overlooked and omitted from our case file data base and cases of IHA could have been missed. Findings in our cohort cannot suggest incidence, and they are likely an underrepresentation of the true prevalence of IHAs.

\section{CONCLUSIONS}

Interhypothalamic adhesions are observed incidentally through the routine acquisition of high-resolution $\mathrm{T} 1$ imaging. In our cohort, most patients had no symptoms referable to the hypothalamus and the finding was made in the absence of other structural abnormalities, specifically midline defects. Because the anomaly is subtle and primarily apparent on isotropic T1 imaging, it is under recognized, especially because smaller IHAs are more likely to be asymptomatic. However, as high-resolution MR imaging techniques become more routinely used, IHAs are likely to be increasingly identified and should prompt detailed scrutiny for additional brain malformation. Although the underlying etiology is unclear, it may be the result of incomplete hypothalamic cleavage, failed apoptosis, or abnormal neuronal migration, the latter being potentially more likely, given the association we found with GMH. While associations between IHAs and other syndromes likely exist, in the appropriate patient population lacking referable symptoms and with few or no other structural abnormalities, interhypothalamic adhesions may be incidental and of no clinical significance.

Disclosures: Farres N. Ahmed_RELATED: Support for Travel to Meetings for the Study or Other Purposes: The University of Colorado Radiology Department partially supported travel and meeting and hotel fees to present the poster at the 2015 ASNR meeting. This is part of the resident travel funds.

\section{REFERENCES}

1. Simon EM, Hevner RF, Pinter JD, et al. Assessment of the deep gray nuclei in holoprosencephaly. AJNR Am J Neuroradiol 2000;21: 1955-61 Medline

2. Simon EM, Hevner RF, Pinter JD, et al. The middle interhemispheric variant of holoprosencephaly. AJNR Am J Neuroradiol 2002;23: 151-56 Medline

3. Barkovich, AJ, Raybaud C. Pediatric Neuroimaging. Philadelphia: Wolters Kluwer Health/Lippincott Williams \& Wilkins; 2012

4. Whitehead MT, Angel JD. Interhypothalamic adhesion in a 9-month-old male with cleft palate. Case Rep Radiol 2013;2013: 197415 CrossRef Medline

5. Whitehead MT, Vezina G. Interhypothalamic adhesion: a series of $\mathbf{1 3}$ cases. AJNR Am J Neuroradiol 2014;35:2002-06 CrossRef Medline

6. Arita K, Ikawa F, Kurisu K, et al. The relationship between magnetic resonance imaging findings and clinical manifestations of hypothalamic hamartoma. J Neurosurg 1999;91:212-20 CrossRef Medline

7. Debeneix C1, Bourgeois M, Trivin C, et al. Hypothalamic hamartoma: comparison of clinical presentation and magnetic resonance images. Horm Res 2001;56:12-18 CrossRef Medline

8. Jung H, Neumaier Probst E, Hauffa BP, et al. Association of morphological characteristics with precocious puberty and/or gelastic seizures in hypothalamic hamartoma. J Clin Endocrinol Metab 2003;88: 4590-95 CrossRef Medline

9. Acosta MT, Walsh KS, Kardel PG, et al. Cognitive profiles of neurofibromatosis type 1 patients with minor brain malformations. $\mathrm{Pe}$ diatr Neurol 2012;46:231-34 CrossRef Medline

10. Lemaire JJ, Nezzar H, Sakka L, et al. Maps of the adult human hypothalamus. Surg Neurol Int 2013;4(suppl 3):S156-63 CrossRef Medline

11. Byerly MS, Blackshaw S. Vertebrate retina and hypothalamus development. Wiley Interdiscip Rev Syst Biol Med 2009;1:380-89 CrossRef Medline

12. Markakis EA. Development of the neuroendocrine hypothalamus. Front Neuroendocrinol 2002;23:257-91 CrossRef Medline

13. Roessler E, Du YZ, Mullor JL, et al. Loss-of-function mutations in the human GLI2 gene are associated with pituitary anomalies and holoprosencephaly-like features. Proc Natl Acad Sci U S A 2003;11: 13424-29 Medline

14. Koutcherov Y1, Mai JK, Ashwell KW, et al. Organization of human hypothalamus in fetal development. J Comp Neurol 2002;446: 301-24 CrossRef Medline 